\begin{tabular}{c}
\hline$A U R, 5$ (1) Oktober 2021 ISSN 2599-0179 (Print) ISSN 2599-0160 (Online) \\
JAUR \\
(Journal of Architecture and Urbanism Research) \\
Available online http://ojs.uma.ac.id/index.php/jaur
\end{tabular}

\title{
PERANCANGAN MANGROVE REHABILITATION CENTER DI BENGKALIS DENGAN PENDEKATAN SIMBIOSIS KISHO KUROKAWA
}

\section{MANGROVE REHABILITATION CENTER DESIGN IN BENGKALIS WITH SYMBIOTIC APPROACH KISHO KUROKAWA}

\author{
Ade Prayetno ${ }^{1)}$, Gun Faisal'), Mira Dharma $S^{3 \text { ) }}$ \\ 1)Mahasiswa Program Studi Arsitektur, Fakultas Teknik, Universitas Riau \\ 2) 3) Dosen Program Studi Arsitektur, Fakultas Teknik, Universitas \\ Diterima: Agustus 2021; Disetujui: September 2021; Dipublikasi: Oktober 2021 \\ *Coresponding Email: adeprayetno2147@student.unri.ac.id
}

\begin{abstract}
Abstrak
Kabupaten Bengkalis diperkirakan memiliki 40.916 Ha hutan magrove dan setiap tahun selalu mengalami penurunan dan kerusakan. Akibat dari rendahnya kesadaran masyarakat khususnya didaerah pesisir dan eksploitasi hutan Mangrove secara berlebihan serta keadaan sosial ekonomi masyarakat Kabupaten Bengkalis yang tersebar dipesisir pantai mengandalkan sumber daya alam kelautan dan pesisir pantai sebagai mata pencaharian masyarakat setempat. Masyarakat melakukan intrusi terhadap ekosistem hutan magrove dengan mengalih fungsikan lahan (magrove) menjadi tambak, pemukiman nelayan, industri dan penebangan untuk berbagai keperluan seperti bahan industri panglung kayu arang, dan sebagai cerocok bangunan. Akibatnya wilayah kabupaten Bengkalis mengalami kerusakan yang cukup parah tepatnya daerah yang berahadapan langsung dengan Selat Malaka yang memiliki gelombang laut yang cukup kuat. Untuk itu agar menyadarkan masyarakat akan pentingnya Mangrove diperlukan Pusat Rehabilitasi konservasi Mangrove yang mana Pusat Rehabilitasi ini berfungsi sebagai pusat pengembangan, penelitian, serta edukasi masyarakat didalamnya terdapat pusat riset, development, laboratorium indoor dan outdoor serta cultivation area. Mangrove Rehabilitation Center ini menggunakan pendekatan simbiosis Kisho Kurokawa yang pada dasarnya memiliki prinsip simbiosis antara alam dan manusia yang dapat memperbaiki pola pikir dan interaksi dalam rancangan yang mengacu pada fungsi pengembangan, penelitian, edukasi, serta rekreasi.
\end{abstract}

Kata Kunci: Bengkalis, Mangrove, Rehabilitation center, Simbiosis, Kisho Kurokawa.

ABSTRACT.

The regency of Bengkalis is estimated to have 40,916 Ha of the Magrove forest and every year has always suffered deterioration and damage. Due to the low awareness of the community, especially in coastal areas and excessive exploitation of Mangrove forests as well as the socio-economic situation of the scattered 
districts of Bengkalis, coastal communities rely on maritime natural resources and coastal coast as a livelihood for local people. The community is intrusion into the Magrove forest ecosystem by enabling the land (Magrove) into a pond, fisherman's settlement, industrial and logging for various purposes such as wood charcoal cassava industrial material, and as a building cerocok. As a result, the area of Bengkalis district suffered damage that is quite severe precisely the area that berahtaps directly with the Straits of Malacca that has a strong sea waves. Therefore, to be aware of the importance of Mangrove Conservation Rehabilitation Center is required where the rehabilitation center serves as a center for Development, Research, and education of the community in which there is a center for research, Development, laboratory indoor and outdoor and cultivation area. The Mangrove Rehabilitation Center uses the symbiotic approach of Kisho Kurokawa which essentially has a symbiotic principle between nature and humans that can improve the mindset and interaction in the design that refers to the function of development, research, education, and recreation.

\section{Keywords: Bengkalis, Mangrove, Rehabilitation Center, Symbiosis, Kisho Kurokawa}

How to Cite: Ade P, Gun F, Mira D. S (2021). Perancangan Mangrove Rehabilitation Center di Bengkalis dengan Pendekatan Simbiosis Kisho Kurokawa .JAUR (Journal of Architecture and Urbanism Research). 5 (1): 42-52 


\section{PENDAHULUAN}

Indonesia memiliki hutan Mangrove terbesar yaitu mencapai $27 \%$ dari luas Mangrove dunia serta $75 \%$ dari total Mangrove di Asia Tenggara. Pada tahun 2000, kementrian Negara dan Lingkungan Hidup (KLH) Republik Indonesia mengatakan luas hutan Mangrove Indonesia mencapai 9,2 juta Ha dengan kondisi baik sejumlah 2,5 $\mathrm{Ha}$, rusak sedang 4,5 Ha, rusak berat 2,1 Ha. Pada tahun 2005 Westland Internasional mempelihatkan fakta bahwa luasan hutan Mangrove di Indonesia mengalami Penurunan hanya tinggal 1,5 juta $\mathrm{Ha}$ saja. Departemen Kehutanan pada tahun 2003 menelusuri bahwa penurunan dan kerusakan mencapai 200 ribu $\mathrm{Ha} /$ tahun.

Terjadinya penurunan secara Pesat ini membawa dampak meningkatnya erosi pantai dan merusak habitat alami fauna di ekosistem seperti ikan, udang, makrobentos, burung dan lain-lain. Hal ini juga mempengaruhi mata pencaharian nelayan di wilayah pesisir. Oleh sebab itu, rehabilitasi hutan Mangrove sangat dibutuhkan untuk menjaga melestarikan ekosistem yang ada. Sehingga dapat mengurangi erosi dan pengikisan pantai.

Kabupaten Bengkalis merupakan salah satu kabupaten/kota di provinsi Riau wilayah mencakup daratan bagian pesisir Timur pulau Sumatera. Wilayah kabupaten Bengkalis terdiri dari pulau dan daratan serta memiliki kawasan pesisir dan laut dengan garis pantai sepanjang $446 \mathrm{Km}$. Kabupaten Bengkalis diperkirakan memiliki $40.916 \mathrm{Ha}$ hutan magrove pada tahun 2011, mengalami penurunan menjadi 33.016 Ha pada tahun 2015 yang apabila dikelola dapat dijadikan objek wisata (Badan Pusat Statistik Kabupaten Bengkalis Tahun 2015).

Pemerintah dan beberapa masyarakat kabupaten Bengkalis sudah berupaya melakukan rehabilitasi hutan Mangrove dengan melakukaan pembibitan dan penanaman Mangrove pada area yang terkena abrasi. Selain itu juga membentuk kelompok-kelompok pengelola Mangrove, Rehabilitasi yang dilakukan belum efektif sebab belum ada wadah pendukung sebagai pemeliharaan. Bibit Mangrove yang ditanam banyak hanyut akibat besarnya gelombang dan arus air laut. Wilayah kabupaten Bengkalis mengalami kerusakan yang cukup parah tepatnya daerah yang berahadapan langsung dengan Selat Malaka yang memiliki gelombang laut yang cukup kuat. Pusat Penelitian dan Analisis Abrasi Pantai Badan Penelitian dan Pengembangan Provinsi Riau (2010) menyatakan abrasi pantai dapat dicegah dengan beberapa cara yaitu : Secara alami, melalui penanaman bakau/magrove atau tanaman jenis lain, bangunan penahan ombak atau turap,dan merubah prilaku kehidupan sekitar pantai.

Akibat dari rendahnya kesadaran masyarakat khususnya didaerah pesisir dan eksploitasi hutan Mangrove secara berlebihan serta keadaan sosial ekonomi masyarakat Kabupaten Bengkalis yang tersebar dipesisir pantai mengandalkan sumber daya alam kelautan dan pesisir pantai sebagai mata pencaharian masyarakat setempat. Masyarakat melakukan intrusi terhadap ekosistem hutan magrove dengan mengalih fungsikan lahan (magrove) menjadi tambak, pemukiman nelayan, industri dan penebangan untuk berbagai keperluan seperti bahan industri panglung kayu arang, dan sebagai cerocok bangunan. Selain itu, analisis yang dilakukan yaitu analisis kelayakan. Pengertian studi kelayakan menurut Andri Kristanto adalah merupakan tahap yang paling penting, karena di dalamnya menyangkut berbagai aspek sistem yang baru yang diusulkan. Sedangkan menurut O'Brien adalah studi awal untuk merumuskan informasi yang dibutuhkan oleh pemakai akhir, kebutuhan sumber daya, biaya, manfaat dan kelayakan proyek yang diusulkan. Pengertian layak disini adalah kemungkinan dari gagasan usaha atau proyek yang akan dilaksanakan memberikan manfaat benefit baik dalam arti financial benefit maupun dalam arti social benefit. (Rambe, 2021) 
Dari beberapa uraian di atas salah satu jalan untuk mewujudkan pencegahan berdasarkan pernyataan Pusat Penelitian dan Analisis Abrasi Pantai Badan Penelitian dan Pengembangan Provinsi Riau (2010), dan untuk menyadarkan masyarakat akan pentingnya Mangrove diperlukan Pusat Rehabilitasi konservasi Mangrove yang mana Pusat Rehabilitasi ini berfungsi sebagai pusat pengembangan, penelitian, pertemuan para pecinta alam, serta edukasi masyarakat didalamnya terdapat pusat riset, development, laboratorium indoor dan outdoor serta cultivation area. Mangrove Rehabilitation Center ini menggunakan pendekatan simbiosis Kisho Kurokawa. Dalam prinsip arsitektur simbiosisnya Kisho Kurokawa memiliki prinsip simbiosis yang bermain dengan alam dan manusia. Maka dari itu tema yang sesuai denga kriteria pendekatan Magrove Rehabilitation Center adalah simbiosis Kisho Kurokawa. Karena melalui pendekatan simbiosis ini akan menciptakan interkoneksi atau hubungan yang baik antara manusia dan alam. Sehingga bangunan Mangrove Rehabilitation Center ini menggunakan material, warna yang tidak merusak alam. Mangrove Rehabilitation Center merupakan wadah pengembangan dan edukasi pembudidayaan mangrove yang erat kaitanya dengan interaksi langsung antara manusia dan alam. Apabila ekosistem alam dapat terjaga maka dampak baik dan manfaatnya kembali lagi kepada manusia itu sendiri. Selain untuk menjaga keselamatan ekosistem alam, Mangrove Rehabilitation Center ini nanti akan menjadi pusat ekowisata mangrove karena memiliki potensi hutan mangrove yang cukup luas.

Bersasarkan Peraturan Menteri Kehutanan No.03/MENHUT-V/2004 tentang rehabilitasi hutan Mangrove adalah upaya mengembalikan fungsi hutan Mangrove yang mengalami penurunan, terhadap kondisi yang dianggap baik dan mampu menjalankan fungsi ekologis dan ekonomis. Rehabilitasi juga dapat disebut sebagai pengelolaan dan pelestarian Mangrove. Serta dua konsep utama yang diterapkan. Pada dasarnya memberikan penjelasan agar tetap lestari Mangrove sangat memerlukan pengelolaan dan perlindungan. Adapun kedua konsep tersebut adalah konservasi hutan Mangrove dan rehabilitasi hutan Mangrove. Fungsi perancangan akan mengacu pada defenisi rehabilitasi Mangrove diatas yaitu sebagai wadah untuk menampung berbagai kegiatan pelestarian Mangrove, seperti pengembangan, penelitian, edukasi , rekreasi dan ekowisata.

Prinsip Simbiosis Kisho Kurokawa, Menurut Irwan (2016), Berdasarkan pemikiran dan karya karya teoritis Kisho Kurokawa ditemukan beberapa konsep perancangan simbiosis yang penting adalah sebagai berikut :

a. Intermediary Space, Digambarkan sebagai ruang yang berfungsi sebagai perantara atau penghubung antara ruang luar dan ruang dalam. Intermediary Space untuk menciptakan hubungan antara dua hal yang berbeda.

b. Konsep Nature Sesuai Kondisi dan Lokasi Tapak, Konsep ditentukan dimana bangunan berada.

c. Simbiosis Traditional and Modren arsitektur, Bentukan bangunan dipengaruhi bentuk tradisional dan arsitektur modern.

d. Mega Structure, Menggunakan Struktur baja dan mengekspos Struktur.

\section{METODE PENELITIAN}

\section{Paradigma}

Perancangan Mangrove Rehabilitation Center dengan pendekatan Simbiosis Kisho Kurokawa ini merupakan wadah bagi masyarakat dan sebagai pusat edukasi untuk melakukaan kegiatan, riset penelitian serta pengembangan Mangrove. Selain itu juga berfungsi sebagai ekowisata. Dengan adanya 
Mangrove Rehabilitation Center ini membuat masyarakat ataupun pengunjung wisatawan lebih memahami bagaimana menjaga serta melestarikan ekosistem alam yang ada terutama hal yang berkaitan dengan Mangrove.

Simbiosis merupakan hubungan saling membutuhkan. Dalam hal ini keberadaan pusat rehabilitasi Mangrove sangat dibutuhkan masyarakat begitu juga dengan Pemerintah dalam mengatasi masalah abrasi membutuhkan peran masyarakat. Sehingga nantinya akan menciptakan interkoneksi atau hubungan yang baik dalam masyarakat dan lingkungan sekitar yang berupaya menyelamatkan dan menjaga ekosistem alam. Apabila ekosistem alam dapat terjaga maka dampak baik dan manfaatnya kembali lagi kepada masyarakat itu sendiri.

\section{Strategi Perancangan}

Strategi perancangan yang dilakukan dalam Perancangan Mangrove Rehabilitation Center dengan Pendekatan simbiosis Kisho Kurokawa yaitu dimulai dengan Teori, Analisa site, analisa fungsi, analisa ruang, program ruang, penzoningan, konsep, penzoningan, tatanan massa, bentukan massa, denah, sistem bangunan, sirkulasi, fasad, konsep desain dan sehingga mendapatkan hasil desain.

\section{Metode Pengumpulan Data}

Dalam Perancangan Mangrove Rehabilitation Center ini menggunakan metode pengumpulan dan pengolahan data menggunakan dua metode yaitu, data primer dan data sekunder. Pengumpulan data primer yaitu dengan proses wawancara, pemetaan potensi kawasan melalui survei langsung (Observasi) dan dokumentasi. Sedangkan metode sekunder menggunakan beberapa cara pengambilan data seperti studi pustaka dan studi banding.

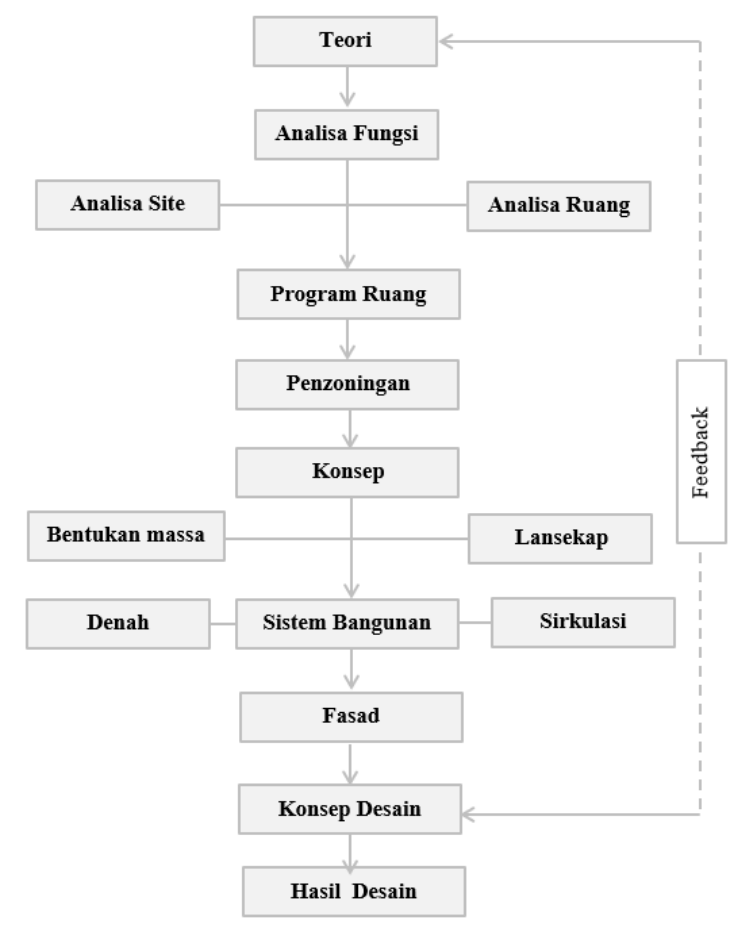

Gambar 1. Bagan Alur Perancangan (Sumber: Observasi Peneliti, 2020)

\section{PEMBAHASAN}

\section{Lokasi Perancangan}

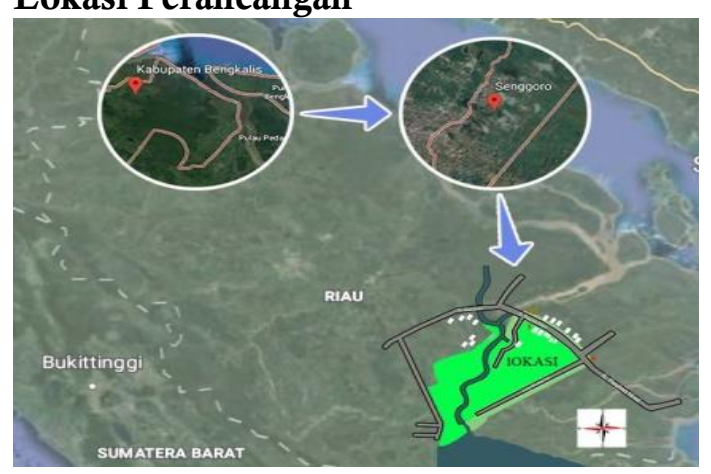

Gambar 2. Lokasi Perancangan

(Sumber: Observasi Peneliti, 2020)

Lokasi tapak berada di J1. Panglima Minal, Desa Senggoro, Kec.Bengkalis, Kabupaten Bangkalis dengan Luas Lahan $\pm 173,742 \mathrm{~m} 2$ (17,4 Ha), KD 40\%, Kontur site Sedikit Bergelombang, Eksisting Lahan kosong dan sedikit Hutan mangrove. Lokasi ini memiliki batas site Sebelah utara berbatasan 
dengan pemukiman warga, Sebelah selatan berbatasan dengan Selat Bengkalis, Sebelah timur berbatasan dengan lahan kosong dan Gang Mayang Sari, Sebelah barat berbatasan dengan Sungai Kecil dan Pemukiman Warga.

\section{Kebutuhan Ruang}

Fasilitas Kebutuhan ruang yang diperlukan dalam perancangan Mangrove Rehabilitation Center sebagai berikut:

Tabel 1. Kebutuhan Ruang

\begin{tabular}{|c|c|}
\hline Fasilitas Ruang & Luas $\left(\mathrm{m}^{2}\right)$ \\
\hline Fasilitas Utama & $1.632,8 \mathrm{~m}^{2}$ \\
\hline Fasilitas Pendukung & $2005,9 \mathrm{~m}^{2}$ \\
\hline Fasilitas Pengelola & $69 \mathrm{~m}^{2}$ \\
\hline Fasilitas Service & $144,3 \mathrm{~m}^{2}$ \\
\hline Fasilitas Ruang Luar & $11.298 \mathrm{~m}^{2}$ \\
\hline $\begin{array}{l}\text { Total Keseluruhan Luas } \\
\text { Bangunan }\end{array}$ & $15.150 \mathrm{~m}^{2}$ \\
\hline
\end{tabular}

(Sumber: Observasi Peneliti, 2020)

\section{Penzoningan}

Pada perancangan Penzoningan dibagi menjadi dua zonasi yaitu Zona publik dan Semi Privat. Adapun zona publik terdiri dari Zona rekreasi, Zona edukasi, dan zona komersil sedangkan zona semi privat yaitu zona pengembangan, zona penelitian, zona servis dan Pengelola.

\section{Konsep}

Konsep pada bangunan Mangrove Rehabilitation Center mengambil konsep simbiosis alam dan manusia, konsep alam di ambil dari buah hasil alam yaitu buah pohon Mangrove (jenis Sonneratia Casiolaris). Bentuk bangunan terinpirasi dari bentukan buah Mangrove yang dipotong menjadi dua bagian, Maka diambil bentuk geometri lingkar buah yang di adopsikan sebagai bentukan fasad dan kelopak sebagai pelidung atau atap bangunan. Konsep Buah mangrove diambil karena buah ini bermanfaat bagi manusia dapat dioalah menjadi makanan seperti dodol, sirup dan lainlain. Selain buah akar Mangrove yang sangat kuat dapat menahan pantai dari gelombang air laut sehingga mencegah terjadinya pengikisan atau abrasi.

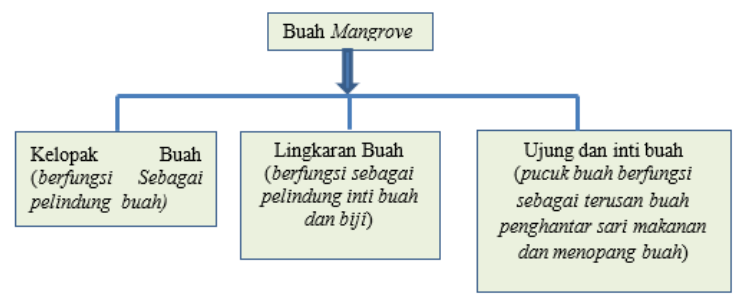

Gambar 3. Bagan Konsep

(Sumber: Observasi Peneliti, 2020)

\section{Konsep Bentuk dan Gubahan Massa}

Gaya bangunan Mangrove Rehabilitation Center menerapkan karakteristik Simbiosis Kisho kurokawa dan prinsipnya. Simbiosis yang berkaitan dengan alam dan manusia. Gaya ekspresi bangunan mempertahankan bentukan alam yang dikemas dalam bentuk modren. Ekspresi interaksi alam dan manusia di ambil dari bentuk geometri lingkaran buah mangrove. Dalam prinsipnya simbiosis memiliki penerapan pola ruang, dan konsep bangunan, dalam segi material lebih menekankan pada material modren sesuai dengan kebutuhan. Penerapan prinsip pada Objek bangunan diharapkan mampu mengakomodasikan aktivitas publik dan ruang sosial. Sehingga pada penerapannya bangunan Mangrove Rehabilitation Center selaras dengan alam dan lingkungan sekitar.

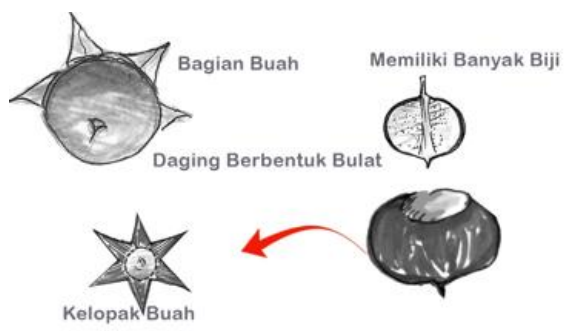

Gambar 4. Konsep Bentuk dan Tatanan Massa (Sumber: Observasi Peneliti, 2020)

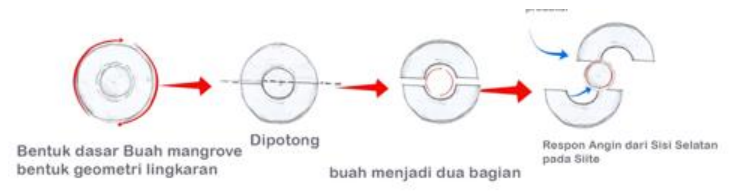

Gambar 5. Konsep Bentuk dan Tatanan Massa (Sumber: Observasi Peneliti, 2020) 


\section{Konsep Massa Bangunan}

Bentukan massa bangunan terinspirasi dari buah mangrove yang berasal dari alam. Bentuk buah yang diambil yaitu bagian-bagian buah seperti pada geometri lingkaran buah yang berbentuk bulat dan memiliki kelopak segitiga. Lengkungan atau lekuk buah sebagai bentuk struktur bangunan dan di adopsi menyerupai akar tanaman mangrove itu sendiri yang mana akar sebagai penopang terkuat dari mangrove sebagai penahan gelombang air laut. Kelopak buah sebagai pelindung buah, sedangkan pada bangunan sebagai pelindung bangunan dan bentukan atap bangunan.

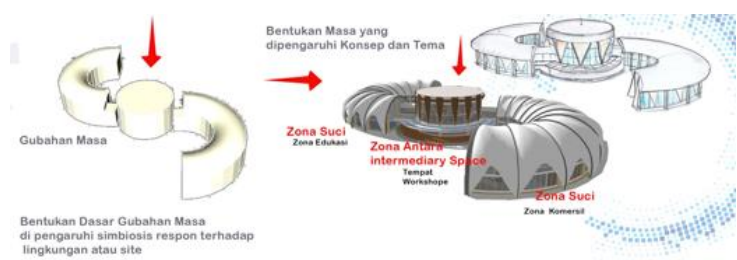

Gambar 6. Visualisasi Bentuk Konsep Bangunan Utama

(Sumber: Observasi Peneliti, 2020)

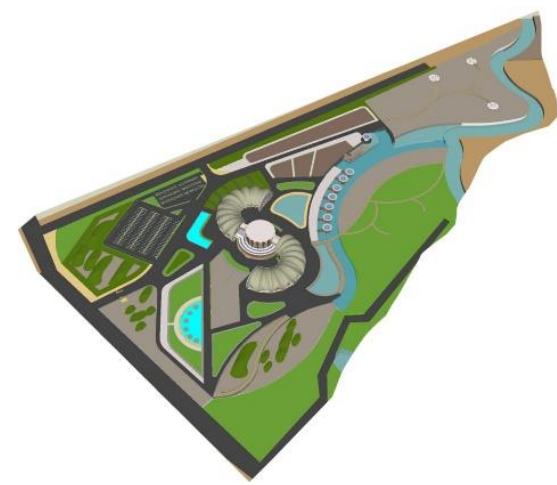

Gambar 7. Visualisasi Bentuk Konsep Kawasan (Sumber: Observasi Peneliti, 2020)

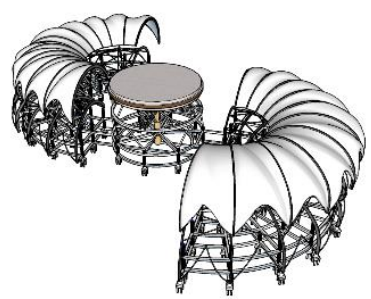

Gambar 8. Visualisasi Bentuk Struktur (Sumber: Observasi Peneliti, 2020)

\section{Konsep Kawasan}

Konsep Kawasan Mangrove Rehabilitation Center menjadi pusat edukasi, wisata dan riset para pecinta alam. Pola bentukan dibentuk mengikuti pola site berdasarkan prinsip symbiosis dan bangunan yang dihubungkan dengan fungsi bangunan berdominan berkaitan dengan kegiatan edukasi dan rekreasi pada area mangrove.

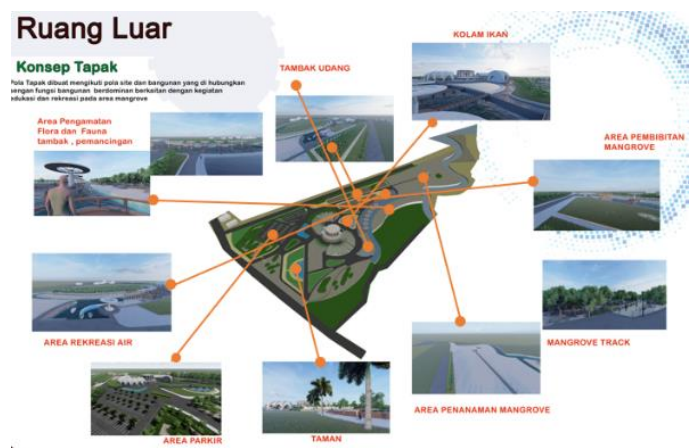

Gambar 9. Visualisasi Bentuk Konsep pada Kawasan (Sumber: Observasi Peneliti, 2020)

\section{Konsep Rencana Tapak}

Pencapaian Tapak

Pencapaian lokasi pada tapak kawasan dibuat menggunakan 1 jalur pada akses masuk dan keluar yaitu melalui j1. Panglima Minal.dan Akses keluar melalui Gang Mayang Sari. Akses jalan ini dapat dilalui oleh kendaraan pribadi dan umum.

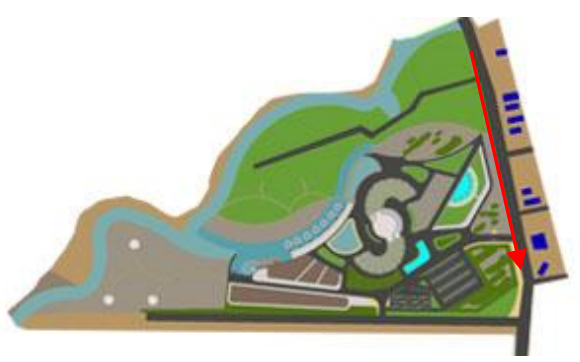

Gambar 10. Konsep Peneapaian Tapak (Sumber: Observasi Peneliti, 2020)

Enterence kawasan diletakkan pada akses masuk tapak, akses tersebut menghubungkan antara area parkir, Taman dan Area Edukasi serta Komersil. 


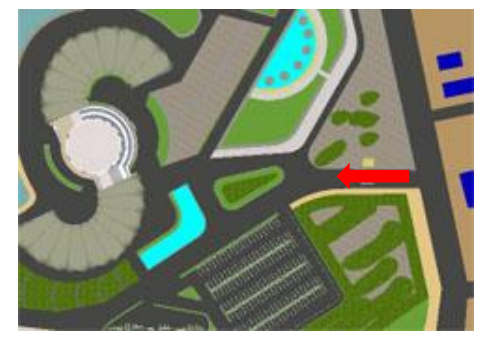

Gambar 11. Enterence

(Sumber: Observasi Peneliti, 2020)

\section{Konsep Tampilan Bangunan}

Konsep alam untuk tampilan bangunan pada Mangrove Rehabilitation Center di Bengkalis, diwujudkan dalam beberapa ide perancangan. Perwujudan konsep Alam dalam tampilan bangunan salah satunya adalah penggunaan lekukan lingkar buah dan bentuk kelopak buah yang menutupi pada bagian fasad bangunan utama.

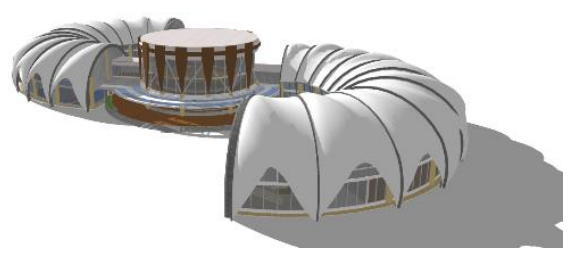

Gambar 12. Konsep Tampilan Bangunan (Sumber: Observasi Peneliti, 2020)

\section{Konsep Zonasi}

Pada Pengembangan Kawasan Mangrove Rehabilitation Center di Bengkalis terbagi menjadi beberapa zona yaitu, zona servis, zona komersil, zona penelitian, zona rekreasi, zona pengembangan, dan zona parkir.

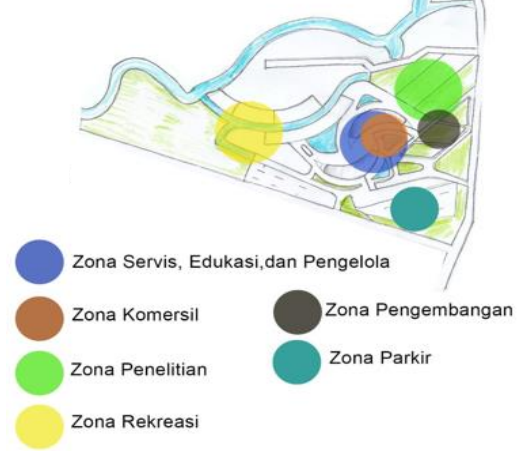

Gambar 13. Konsep Zonasi

(Sumber: Observasi Peneliti, 2020)

\section{SIMPULAN}

Kesimpulan dari rancangan Mangrove Rehabilitation Center dengan pendekatan Simbiosis Kisho Kurokawa ini adalah sebagai berikut :

Mangrove Rehabilitation Center di Bengkalis di rancang sebagai wadah pusat pengembangan, edukasi, penelitian segala jenis tanaman mangrove. Yang mana didalamnya menyediakan fasilitas-fasilitas penelitian, edukasi tanaman mangrove. Fasilitas utama Mangrove Rehabilitation Center adalah menyediakan ruang edukasi dengan adanya kelas teori, ruang penelitian, area budidaya, serta rekreasi atau berwisata sambil belajar menanam mangrove. Ruang gallery dan workshop sehingga masyarakat, baik komunitas pecinta alam dapat saling bertukar pikiran di dalamnya. Menurut Irwan (2016), Berdasarkan pemikiran dan karya karya teoritis Kisho Kurokawa ditemukan beberapa konsep perancangan simbiosis yang penting adalah sebagai berikut :

a. Intermediary Space, Digambarkan sebagai ruang yang berfungsi sebagai perantara atau penghubung antara ruang luar dan ruang dalam. Intermediary Space untuk menciptakan hubungan antara dua hal yang berbeda.

b. Konsep Nature Sesuai Kondisi dan Lokasi Tapak, Konsep ditentukan dimana bangunan berada.

c. Simbiosis Traditional and Modren arsitektur, Bentukan bangunan dipengaruhi bentuk tradisional dan arsitektur modern.

d. Mega Structure Menggunakan Struktur baja dan mengekspos Struktur.

Penerapan Simbiosis memberikan suatu ekpresi interaksi yang yang ingin di tampilkan oleh perancang melalui bangunan Mangrove rehabilitation menngunakan bebrapa konsep simbiosis yaitu intermediary Space, konsep Nature, Simbiosis Traditional and Modren arsitektur dan 
Mega structure menjadi satu kesatuan konsep yang diterapkan dalam fungsi perancangan. edukasi dan interaksi dengan tampilan dan keindahan yang dapat dinikmati melalui arsitektur bangunannya.

\section{DAFTAR PUSTAKA}

Aqsa, Muhammad 2010. Rehabilitasi Dan Konservasi Mangrove Dalam Menunjang Konservasi Laut Daerah Sela

Tiworo. https://mimpi22.wordpress.com/2010/10/12/re habilitasi-dan-konservasi-mangrove-dalammenunjang-kawasan-konservasi-laut-daerah-kkldselat-tiworo/. (Diakses tgl 19 maret 2020).

[BPS] Badan Pusat Statistik Kabupaten Bengkalis. 2015. Kabupaten Bengkalis dalam Angka 2016. Bengkalis.

Irwan, Adi. 2016. Perancangan Tourism Centre Di Singosari Tema Simbiosis Arsitektur. Skripsi tidak
Selain itu bangunan ini juga memberikan suatu diterbitkan. Jurusan Arsitektur. Fakultas Sains Dan Teknologi. Universitas Islam Negeri Sultan Maulana Malik Ibrahim Malang.

Jencks, C. 1997. Theory And Manifestoes. New York: Academy Edition

Kurokawa, Kisho 1991. Intercultural Architecture - The Philosophy of Simbiosis: London, Academic Edition.

Peraturan Menteri Kehutanan No.03/MENHUTV/2004. Pedoman Pembuatan Tanaman Rehabilitasi Mangrove Gerakan Rehabilitasi Hutan dan Lahan.

Rambe, Y. S. (2021). Analisis Kelayakan Fungsi Wisata Sebagai Strategi Pengembangan Bumi Perkemahan Sibolangit. Jaur (Journal of Architecture and Urbanism Research), 4(2), 181-194. https://doi.org/10.31289/jaur.v4i2.4975 